lighted by electricity. The total cost including equipment is $\$ 15,000$.

The cottage is designed for the moderately advanced cases for whom it is necessary to furnish accommodations for the night as well as treatment during the day. Food for the patients will be prepared and served in the day camp, which is immediately adjacent, and precisely the same routine of treatment will be carried out. It is hoped to build a group of cottages about the camp as a center.

\section{A CURSORY REVIEW OF SURGICAL METHODS FOR THE EXTIRPATION OF HEMORRHOIDS.}

BY T. CHITTENDEN HILL, M.D.,
Surgeon to the Rectal Department of the Boston Dispensary, Boston,
Mass.

THE majority of patients, and more physicians than is generally supposed, have difficulty in believing that hemorrhoids can be permanently cured by operation.

However extravagant this assertion may appear, as the result of personal experience I believe it to be a fair statement of the prevailing opinion concerning a most effective and beneficent surgical procedure which is very generally permanent in its results.

It matters little which of the popular methods - the ligature, clamp and cautery, linear or circular excision (Whitehead's operation) - the surgeon may elect, if properly performed the result should be ideal, and, so far as the hemorrhoidal disease is concerned, there should rarely be any recurrence. I use the word "rarely" advisedly, for surgical experience has taught that, in a certain percentage of cases, all of the hemorrhoids will not have developed before middle life.

Goodsall, of London, after an operative experience of thirty-six years at St. Mark's Hospital for diseases of the rectum, in connection with a large private practice along the same lines, says that "the operation [ligature] is not followed by recurrence if all the piles present are completely removed in a patient above forty years of age. When the patient is under forty years, all the piles may not have developed, so that later a second operation may be required for the removal of piles matured in the interval."

Clinical statistics demonstrate that about $25 \%$ of hemorrhoidal cases are under forty years of age, and for such cases the Whitehead operation, which removes the pile-bearing area, should be chosen if the patient is insistent upon an absolute guaranteed cure. Still, in these younger subjects, it is the rule to find only one or two tumors that require removal, and to excise the lower end of the rectum for so trivial an affair seems hardly justifiable.

The recurrences after these smaller operations are not numerous, for the scar tissue left after removing one or two tumors is generally sufficient to support the remaining vessels and prevent their becoming varicose.

To emphasize the vague notions so many patients have in regard to the hemorrhoidal operation, a recent case extremely typical of many others is here cited.

A lady fifty-two years of age had been troubled with bleeding and prolapsing hemorrhoids for twenty-five years. The hemorrhages in the beginning were of little moment and took place only when at stool, but during this long period she had never for any length of time been entirely free from them. For years the tumors prolapsed, making it necessary to replace them after dejection, and of late, even when walking, they were apt to protrude. Within the last three weeks the hemorrhages had been frequent and profuse, both when at toilet and at other times. There had been for the past few years a constant mucous discharge, sticky and tenacious in character, which was the source of much annoyance. She complained of feeling weak and easily exhausted after slight exertion. Her feeble condition and waxy complexion made it at once apparent that she was suffering from some form of extreme anemia.

She was referred by her family physician, who for over three years had been urging her to have an operaation. She came with many misgivings and wished to know if there was any treatment without an operation. Upon examination I found six large and very vascular internal hemorrhoids which bled at the slightest touch. It was explained to her that an operation was the quickest and safest way to perfect relief, and that the operation could be easily managed under local anesthesia. (Like many other patients she was very positive that ether was contra-indicated in her case.) Under local anesthesia each tumor was carefully dissected well up into the rectum and a linen ligature tied about its pedicle and the pile amputated. Some irregular tags of redundant skin (external piles) were trimmed away.

The operation was painless and six days later she left the hospital and returned home to be with her family, the following day being Christmas.

When six weeks later this lady returned to my office, her general condition had greatly improved and her whole general aspect was most striking. Upon one point she wished information. She had never believed an operation could give her such relief, but how long would it be before they grew again? Upon being assured there was no possibility of recurrence after the operation she had had she was inclined to be incredulous, and remarked that a number of her friends had undergone operation but were now in about the same condition as before. One in particular affirmed that her doctor stated he had removed the remarkable number of 21 hemorrhoids, yet still others had returned to give her much distress.

While writing this paper I asked another of my hemorrhoidal cases, on the sixth day after his operation, if he could explain to me why a person suffering from hemorrhoids would put up with so much inconvenience rather than have operation. He had been operated upon by the clamp and cautery method ten years before, but had never been completely relieved of his protusions; the piles would prolapse at the most inopportune times and places, so that he was very miserable until he could retire and replace them.

His reply was instructive and rather emphatic. "Yes, doctor, I can tell you. There are two reasons. The operation, the way it was done 
ten years ago, was something fierce, and I don't believe there were many of them cured at that. Do you know, if I live to be a hundred I shall never forget the tortures I suffered during the first week after the operation. They plugged me with cotton so that it was impossible to pass wind, and the feeling was as though some one was trying to force a red hot auger up my rectum."

The error of underestimating the inconvenience that hemorrhoids may be to a given individual is apt to lead a physician to prescribe an ointment or suppository that may or may not be of some benefit. While the use of such remedies at times is indicated and will afford much relief, on the other hand their importance must not be overestimated, and the patient should understand clearly that they are but palliative measures. Internal hemorrhoids in the first stages of their development, that is, small varicosities that bleed readily but do not protrude, are sometimes amenable to this form of treatment, but when they have reached the stage of protruding when at stool, the only rational treatment that offers any hope of cure lies in operation. For the physician to prescribe ointments for this latter class without explaining the nature of his treatment is very apt to prove misleading. The patient, finding his prescription is not having the desired effect, and with the mistaken notion that he has not got the right formula, proceeds to test the various nostrums which are at the present time so widely advertised. It is not an unusual experience to see patients who had used hundreds of dollars' worth of these advertised pile cures persisting in their use until their physical condition was greatly weakened and their lives rendered unbearable as the result of loss of blood and great suffering.

Among other causes which have helped to bring this operation in disrepute are the following: The fear of such complications as abcesses, fistula, stricture, fissure and ulceration. In answer to this objection I can affirm that in over 300 hemorrhoidal operations in my practice during the last four years none of these complications have ever occurred, and I believe that any one who has a fair regard for surgical cleanliness at the time of operation and will take the pains to care for the after-treatment of these wounds nced have no fear of any of these disasters.

Another factor which, perhaps, is the most important of all, is that the operator, not the operation, is at fault. The operation is simple but often too baffling for one of little surgical experience. The anus, rugose and elastic as it is, even after dilatation of the sphincters, renders it an easy matter to overlook the smaller tumors when obscured by the blood incident to the operation. The result is that two or three hemorrhoids are left, and the patient, after a varying lapse of time, is again inconvenienced as much as before. For many people one pile is as distracting as several, and is quite sufficient to set up the whole train of symptoms associated with this disease.

\section{SURGICAL TREATMENT.}

Though many operations have been and are constantly being suggested for the cure of internal hemorrhoids, the clamp and cautery, circular incision (Whitehead's operation) and the ligature include all that have ever received any general recognition. Any of these procedures if intelligently carried out will prove universally successful.

\section{WHITEHEAD'S OPERATION.}

This operation aims to forestall the possibility of any recurrence by removing the whole pilebearing area. In certain varicose conditions associated with a general prolapse of the mucous membrane this operation is without doubt the most effective. By excising en masse the redundant mucous membrane, the anal canal is made to assume more nearly its normal appearance. It is, however, only in those cases in which the prolapse is the predominating feature that this operation has anything to commend it over the simpler methods of the ligature or cautery.

Its disadvantages are that it is a tedious operation entailing considerable loss of blood which always requires general anesthesia, confinement of the bowels for five or six days, and, occasionally, even with the most painstaking technic and after-treatment, primary union is not secured. When primary union is not secured and ulceration at the point of union of the skin and mucous membrane takes place, there is much danger of anal stricture. If the mucous membrane has not been very accurately coapted, there is risk of its being everted, thereby causing moisture and pruritus.

\section{CLAMP AND CAUTERY.}

This deservedly popular method needs no commendation. It is applicable for all forms and conditions of hemorrhoids, and formerly I employed it exclusively, but a larger expcrience has led me to believe that the advantages of the cautery over the ligature are more matters of technic than anything else.

In either procedure the operators of greatest experience dissect up the hemorrhoidal tumor until it is attached by a narrow pedicle. One applies a clamp, cuts away the pile and sears the stump with a red hot iron. The other ties a finen linen ligature about the pedicle and removes the pile. The ligature comes away in three or four days together with the small amount of tissue anterior to it. It would seem that the question whether the normal process of repair is retarded more by the ligature or the charred stump is a good deal like splitting hairs. As to the amount of pain, I believe there is little difference. It is only in exceptional cases that either operation, when properly performed, should occasion more than a little soreness or discomfort.

\section{THE LIGATURE OPERATION.}

This operation, which has always been regarded as one of the most effective methods at our disposal for the cure of internal hemorrhoids, is 
at the present time employed almost universally among proctologists. Even those who formerly favored the clamp and cautery, circular or linear excision, now prefer this method for the majority of cases because it can be quickly and easily accomplished under local anesthesia.

I have previously described the technic of this operation with illustrations (Boston Medical and Surgical Journal, April 11,1907$)$ as it is practiced under local anesthesia, and for this reason it is omitted here.

\section{Elinical gDepartment.}

SOME INTERESTING AND UNUSUAL CASES FROM THE ORTHOPEDIC CLINICS OF THE RHODE ISLAND AND ST. JOSEPH'S HOSPITALS.

Case 1. Fracture Dislocation of the Fourth Cervical Vertebra with Recovery.

Case 2. Ankyiosis of the KneE following Local Tuberculosis.

Case 3. Madelung's Deformity.

Case 4. Madelung's Deformity.

Case 5. Congenital Deformity of the PhaLANGES.

$$
\begin{aligned}
& \text { BY FRANK E. PECKHAM, M.D., PROVIDENCE, R. I., } \\
& \text { AND } \\
& \text { ROLAND HAMMOND, M.D., PROVIDENCE, R. I. }
\end{aligned}
$$

THE following cases are reported because of their unusual nature or because they presented features of especial intcrest.

CASE 1. FRACTURE DISLOCATION OF THE FOURTH CERVICAL VERTEBRA WITH RECOVERY.

J. M., age fifty, came to the Out-Patient Department of the Rhode Island Hospital, Jan. 30, 1906, complaining of pain and stiffness in the neck and shoulders and of numbness and tingling in the fingers of both hands. Four months previously, while partially intoxicated, he had fallen down a flight of steps, twelve or thirteen in number, landing at the bottom on the back of his neck. He got up immediately and walked upstairs, complaining of no inconvenience at the time. A few days later, however, he noticed pain and stiffness in the neck, radiating to both shoulders, which became progressively worse. The pain was of a tearing nature, worse in the morning and during damp weather. For the past two months the tips of all the fingers had felt numb; the left leg was also weak, and the knee felt as if it might give way under him. Since the accident he had fallen twice, landing on the knees in both cases. He had been unable to work since his injury, and had lost 12 to $14 \mathrm{lb}$. in weight.

Previous health: Usually well except for a series of peritonsillar abscesses which had appeared at irregular intervals since 1874 . The last attack had come about two months before his appearance at the hospital. He had been ill for a week, spitting up large quantities of pus (?).

Physical examination: Showed a prominent kyphos involving the third, fourth and fifth cervical vertebræ. All motions of the head and neck, especially rotation, were much restricted. The thoracic and lumbar spine was rigid in backward but flexible in lateral bending. The skin, especially of the hands, was cold and clammy. General condition of the patient not good. Temperature, 99.8. Pulse, 140 . Heart sounds, clear. Knee jerks very active, but no ankle clonus present. Grasp of the hands fair.
The Roentgen plate in the antero-posterior view showed nothing abnormal. The lateral view, however, showed a dislocation backward between the third and fourth cervical vertebræ with fracture. The interesting thing to note is the small space left for the spinal cord to occupy.

Rectification as a treatment was submitted to the patient, but, in view of the unfavorable prognosis given, was decided against.

April 21, 1907, the patient reported at request, and presented every appearance of health. He still carried his head rigidly, and the kyphos was still present, though less marked. He had worked steadily for the past few months, had gained about $23 \mathrm{lb}$., had a good appetite, and complained of no discomfort when working. His fingers were somewhat clumsy and not so useful as before the accident, but he had very little numbness in them. Another Roentgen plate showed practically no change in the bony structures.

Dec. 19, 1908. The patient had no pain nor inconvenience connected with his injury. The kyphos had been rounded off and was scarcely visible. There was marked thickening in the region of the kyphos, and movements of the neck were somewhat restricted. Fig. 2 shows the present condition of the vertebral column. The patient is in poor general health. His physician, Dr. T. H. Murphy, of Pawtucket, reports that he is suffering from diabetes, which has pro gressed rapidly of late.

The above case is remarkable for the severe damage done to the vertebral column, with apparent slight injury to the spinal cord, and ultimate recovery of its functions.

CASE 2. ANKYLOSIS OF THE KNEE FOLLOWING LOCAL TUBERCULOSIS.

M. A., age nineteen, a school teacher, was referred to the Rhode Island Hospital for treatment of an ankylosed knee-joint, and gave the following history:

At five years of age the left knee began to swell without any known cause, and was associated with considerable pain. This continued for three years, during which time the leg became flexed and finally ankylosed. There had been no pain nor tenderness for several years.

Examination: The left knee was moderately swollen and completely ankylosed at an angle of $120^{\circ}$. No bony points around the joint could be made out except the patella, the joint fecling like one continuous bony swelling of fairly regular contour. Shortening as measured along the line of contour of the leg was two inches.

The Roentgenogram shows a unique condition. (Fig. 3.) The femur and tibia appear as though welded together and bent at nearly a right angle. The medullary cavity of the femur and tibia are continuous. The articular surfaces of the lower end of the femur and the upper end of the tibia are wanting, except for slight swellings which mark their normal positions. The patella is seen firmly attached to the front surface of the femur at about its normal position. The fibula, seen in its upper part, is apparently normal. Otherwise the normal structures of the joint are lost. July 12, 1906. Operation: Excision of the knee was performed, and a wedge-shaped piece of bone about two inches wide at the anterior part of the joint was removed. The leg could now $\mathrm{cc}$ brought into full extension with complete apposition of the bony surfaces. The leg was put in plaster from the foot to the groin, which was removed forty-one days later. Two months later she was discharged to the 